\title{
COMPARISON BETWEEN LIGNOCAINE HYDROCHLORIDE AND ROPIVACAINE HYDROCHLORIDE AS LUMBOSACRAL EPIDURAL ANAESTHETIC AGENTS IN GOATS UNDERGOING LAPAROSCOPY ASSISTED EMBRYO TRANSFER
}

\author{
Anubhav Khajuria ${ }^{1}$, Mujeeb ur Rehman Fazili², Riaz Ahmad Shah ${ }^{3}$, \\ Maajid Hassan Bhat ${ }^{3}$, Firdous Ahmad Khan 3 , Syed Hilal Yaqoob ${ }^{4}$, \\ Niyaz Ahmad Naykoo ${ }^{3}$, Nazir Ahmad Ganai ${ }^{3}$
}

${ }^{1}$ Division of Veterinary Surgery and Radiology, Faculty of Veterinary Science \& AH, Sher-e-Kashmir University of Agricultural Sciences and Technology of Kashmir, India ${ }^{2}$ Veterinary Clinical Service Complex, Faculty of Veterinary Science \& AH, Sher-e-Kashmir University of Agricultural Sciences and Technology of Kashmir, India ${ }^{3}$ Centre of Animal Biotechnology, Faculty of Veterinary Science \& AH, Sher-e-Kashmir University of Agricultural Sciences and Technology of Kashmir, India ${ }^{4}$ Department of Animal Production, College of Food and Agricultural Sciences, King Saud University, Riyadh, Kingdom of Saudi Arabia

Received 5 April 2014; Received in revised form 9 June 2014; Accepted 16 June 2014

\begin{abstract}
Goats ( $\mathrm{n}=12$ ) undergoing laparoscopy assisted embryo transfer were randomly allotted to two groups (I and II) and injected lignocaine hydrochloride $(4 \mathrm{mg} / \mathrm{kg})$ or ropivacaine hydrochloride $(1 \mathrm{mg} / \mathrm{kg})$ at the lumbosacral epidural space. The animals were held with raised hind quarters for the first three minutes following injection. Immediately after induction of regional anaesthesia, they were restrained in dorsal recumbency in the Trendelenburg position in a cradle. Laparoscopy was performed after creating pneumoperitoneum using filtered room air. The mean $( \pm$ S.E) induction time in animals of group I was significantly shorter $(5.33 \pm 0.61 \mathrm{~min})$ than those belonging to group II $(12.66 \pm 1.99 \mathrm{~min})$. Complete analgesia developed throughout the hind quarters and abdomen for $30 \mathrm{~min}$ and $60 \mathrm{~min}$ in group I and II animal's respectively. Unlike animals of group I, group II goats continued to show moderate analgesia for 180 minutes. The motor activity returned after a lapse of $130.00 \pm 12.64$ $\mathrm{min}$ and $405.00 \pm 46.31 \mathrm{~min}$ respectively. Occasional vocalization and struggling was noticed in two goats one from each group irrespective of the surgical manipulations during laparoscopy. The rectal temperature and respiration rates showed only non-significant increase, but the heart rate values were significantly higher $(\mathrm{P}<0.5)$ up to $150 \mathrm{~min}$ in animals of both the groups when compared to their baseline values. From this study, it was concluded that both anaesthetic agents produced satisfactory regional anaesthesia in goats undergoing laparoscopy. However, considering the very long delay in regaining the hind limb motor activity, the use of ropivacaine may not be recommended for this purpose. Supplementation of sedative/tranquilizer with lumbosacral epidural anaesthesia needs evaluation.
\end{abstract}

Key words: epidural anaesthesia, goat, laparoscopy, lignocaine, ropivacaine

\section{INTRODUCTION}

In small ruminants, laparoscopy has most frequently been performed under local infiltration of the anaesthetic at the portal sites along with sedation/tranquilization $(1,2)$.

Corresponding author: Associate Prof. Mujeeb ur Rehman Fazili, PhD E-mail address: fazili_mr@yahoo.co.in

Present address: Veterinary Clinical Service Complex, Faculty of

Veterinary Sciences \& AH, Sher-e-Kashmir University of Agricultural

Sciences and Technology of Kashmir, Shuhama, Srinagar, 190006,

Jammu and Kashmir, India.

Phone: +91-9419095830

Copyright: (C) 2014 Khajuria A. This is an open-access article published under the terms of the Creative Commons Attribution License which permits unrestricted use, distribution, and reproduction in any medium, provided the original author and source are credited.

Competing Interests: The authors have declared that no competing interests exist.

Available Online First: 26 June 2014

http://dx.doi.org/10.14432/j.macvetrev.2014.06.017
Although easy to perform, the local infiltration has several disadvantages including need for larger volume of anaesthetic (propensity for toxicity), non homogenous tissue perfusion and delayed wound healing $(3,4,5,6)$ that could be avoided by the use of a suitable regional anaesthetic procedure. The lumbosacral (L6-S1) epidural anaesthesia provides excellent conditions for undertaking conventional abdominal surgical procedures such as caesarean section, cystorrhaphy and ventrolateral hernias $(5,7)$. Although frequently used for conventional surgeries, the use of lumbosacral epidural anaesthesia in goats undergoing laparoscopy has not been reported to date. Satisfactory relaxation of the abdominal musculature expected following 
epidural anaesthesia may increase the intra-abdominal space and therefore make manipulations easier during laparoscopy.

Lignocaine hydrochloride is the most widely used local anaesthetic $(6,8)$. Ropivacaine hydrochloride, a recently developed agent (9) has not been used widely in veterinary practice. Preliminary reports indicate that as an epidural anaesthetic, ropivacaine is effective and safe in healthy and uremic caprines $(10,11,12)$. In human practice, advantages like lower propensity for motor blockade and reduced central nervous system and cardio toxicity have been reported (13).

The present study evaluated lignocaine hydrochloride and equipotent dose of ropivacaine hydrochloride as lumbosacral anaesthetic agents in goats undergoing laparoscopy assisted embryo transfer.

\section{MATERIALS AND METHODS}

The present study was conducted on twelve clinically healthy adult Pashmina and Bakerwal female goats undergoing laparoscopy assisted embryo transfer. Standard management, feeding schedule, regularly deworming and vaccination practices were followed in the farm to maintain all the animals. All the goats were fasted for 24 to 30 hours preoperatively. The study protocol was approved by the Institutional Animal Ethics Committee (IAEC)

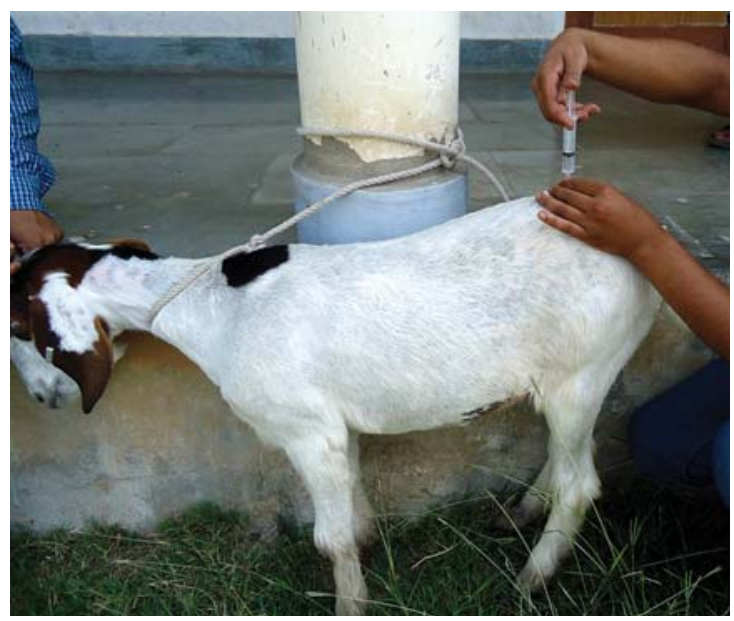

Figure 1. Injecting lumbosacral epidural anaesthetic in a standing Bakerwal doe held straight against a concrete wall of Faculty of Veterinary Sciences \& AH, Shere Kashmir University of Agricultural Sciences and Technology of Kashmir, Srinagar, Kashmir, India. Two days prior to the planned laparoscopy, the animals were thoroughly examined, weighed and their ventral abdomen clipped and shaved properly. They were assigned randomly to two groups (I and II) and subjected to lumbosacral epidural anaesthesia using lignocaine hydrochloride (Inj. Lox 2\%, Neon Laboratories, India) $4 \mathrm{mg} / \mathrm{kg}$ or ropivacaine hydrochloride (Ropin 0.5\%, Neon Laboratories, India) $1 \mathrm{mg} / \mathrm{kg}$ respectively. The age (mean $\pm \mathrm{S} . \mathrm{E}$ ) of the goats belonging to group I and II (assessed from the farm records) was $26.00 \pm 1.26$ months and $21.00 \pm 1.34$ months. They weighed (mean \pm S.E) $31.00 \pm 2.63 \mathrm{~kg}$ and $30.50 \pm 1.56 \mathrm{~kg}$ respectively.

The lumbosacral space was located as a depression on the dorsal midline just caudal to the arbitrary line joining the anterior borders of the ilia. The site was clipped; shaved and applied 70\% isopropyl alcohol. The animal was restrained in standing position against a concrete wall and $2 \%$ lignocaine hydrochloride $(0.5 \mathrm{ml})$ deposited subcutaneously at the injection site. A G-18 (3.85 cm length) hypodermic needle was used to deposit the local anaesthetic solution following the 'hanging drop' and 'flow without resistance' methods (Figure 1). The needle was subsequently withdrawn and the hind limbs of the animal lifted to approximately $45^{\circ}$ from the ground level for 3 minutes (Figure 2).

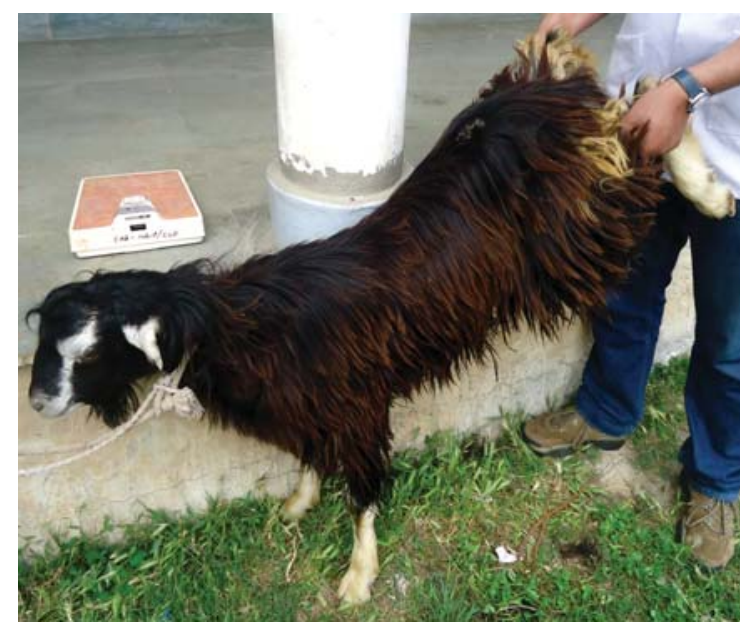

Figure 2. Bakerwal goat held with raised hind quarters immediately after lumbosacral epidural deposition of local anaesthetic 
The animals were subsequently released and allowed to stand on a level ground till satisfactory induction indicated by the paralysis of the animal's hind-limbs and loss of sensation and reflexes (Figure 3).

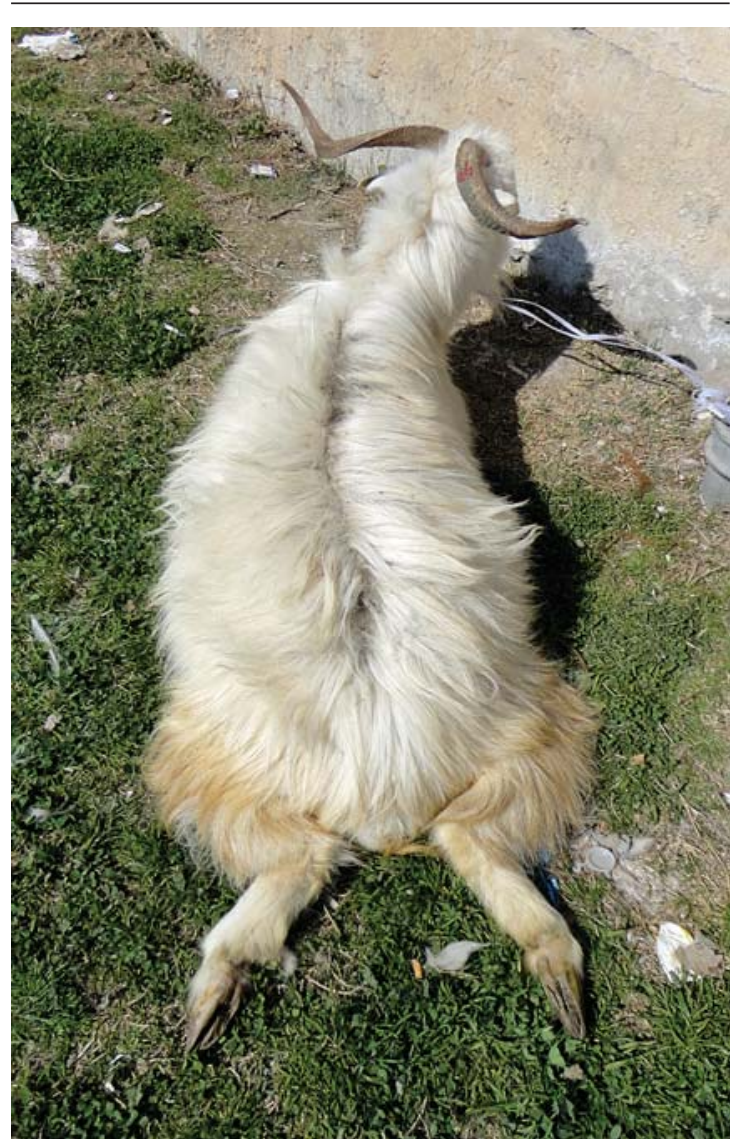

Figure 3. Pashmina goat in a typical posture after induction with lumbosacral epidural anaesthesia

Immediately after induction of anaesthesia, the goats were shifted and restrained in dorsal recumbency in a cradle for laparoscopic intervention. The head region of the goat was lowered (Trendelenburg posture) to $45^{\circ}$ angle with the level of the flooring. The shaved abdominal area was scrubbed and draped properly for aseptic surgery. Pneumoperitoneum was created with the use of a Veress needle. Two ports (one at linea alba and the second 5 to $6 \mathrm{~cm}$ lateral to it) were created 3 to $3.5 \mathrm{~cm}$ cranial to the mammary glands, one for introduction of the laparoscope and the other for passing the grasping forceps. After visualizing the pelvic genital tract, the uterine horn was grasped, the mid-ventral portal site was enlarged to evacuate air and to pull out the uterus for transfer of the embryos. The embryo transfer was followed by withdrawal of the laparoscopic instruments. The duration (mean \pm S.E) for which pneumoperitoneum was maintained (laparoscopy period) in goats of the two groups was $19.16 \pm 2.38 \mathrm{~min}$ and $13.16 \pm 2.53 \mathrm{~min}$ respectively. The midline abdominal opening only was sutured routinely in layers. The portal sites were sprayed with antiseptic cum fly repellent topical preparation. The total surgical time (mean \pm S.E) in goats of the two groups was $61.66 \pm 15.63 \mathrm{~min}$ and $62.50 \pm 7.53 \mathrm{~min}$ respectively.

The animals were shifted and released in the recovery area. They were continuously watched and repeatedly evaluated up to complete recovery from anaesthesia. Analgesic (meloxicam, $0.2 \mathrm{mg} / \mathrm{kg}$ ) and antibiotic (amoxicillin-dicloxacillin, $0.5 \mathrm{~g}$ ) both IM were given just before leading the animals to a pen adjacent to the shed for the main flock. The animals were watched and their incision sites dressed daily till the removal of the cutaneous sutures on day 10 postoperatively.

The onset, depth and duration of analgesia and recovery were determined by noticing the sensory and motor responses in various caudal body regions. Sensory responses to the pin pricks and surgical interventions and manipulations were recorded in the perineal, abdominal $(5 \mathrm{~cm}$ cranial to mammary glands) and umbilical (over linea alba, and bilaterally $5 \mathrm{~cm}$ lateral to linea alba) regions. Anal reflex, tail analgesia, analgesia of perineum and hind limb pedal reflexes were also assessed. The sensory reactions and motor deficit were graded on a 0 to 3 score scale as per the protocol described by Amarpal et al. (14). The induction time, duration of surgery and pneumoperitoneum and the total duration of anaesthesia were also recorded.

Clinical parameters (rectal temperature, heart rate and respiration rate) and the analgesic scores were recorded immediately before lumbosacral epidural administration of the anaesthetic $\left(\mathrm{T}_{0}\right)$, immediately after induction of anaesthesia $\left(\mathrm{T}_{1}\right)$, followed by every 15 minutes up to 1 hour and every $30 \mathrm{~min}$. up to 240 minutes. After that period, clinical parameters and the analgesic scores were recorded every 60 minutes till complete recovery from anaesthesia.

For the evaluation of analgesia score, Kruskal-Wallis H test (non- parametric) was used for the comparison of (mean \pm S.E) values. The data for clinical parameters were analyzed by ANOVA for repeated measures for comparison of (mean \pm S.E) values between and within groups using SPSS (20) version for windows. Dunett's t-test was used to determine time at which treatment response differed from baseline. The values of the clinical parameters were considered as significant at $\mathrm{P}<0.05$. 


\section{RESULTS}

The weight and age (mean \pm S.E) of the goats included in the two separate groups of this study were similar and did not show any significant $(\mathrm{P}>0.05)$ difference.

Restraining the animal adjacent to a concrete wall while injecting local anaesthestic into the lumbosacral epidural space avoided movement of the animal. The deposition of the anaesthetic in the epidural space was easily accomplished in all the animals. However in one goat from group I, the spinal fluid appeared at the hub of the needle. In this animal, the needle was withdrawn carefully till the flow stopped and the anaesthetic was injected.
In animals of group I, the analgesia right from the anus to the umbilical area was complete following lumbosacral epidural anaesthetic injection up to T-30 (Figure 4-13). The analgesia started declining rapidly from $\mathrm{T}-45$. The analgesia vanished completely at T-180. In animals of group II, all the above mentioned areas and structures developed complete analgesia up to T-60. The analgesia started declining progressively from T-90 and vanished completely at T-540. Moderate analgesia persisted in most of the areas up to T-180.

In animals of group I, full motor activity was regained in $130.00 \pm 12.64 \mathrm{~min}$ (mean \pm S.E). However, in those belonging to group II it took $405.00 \pm 46.31$ minutes.

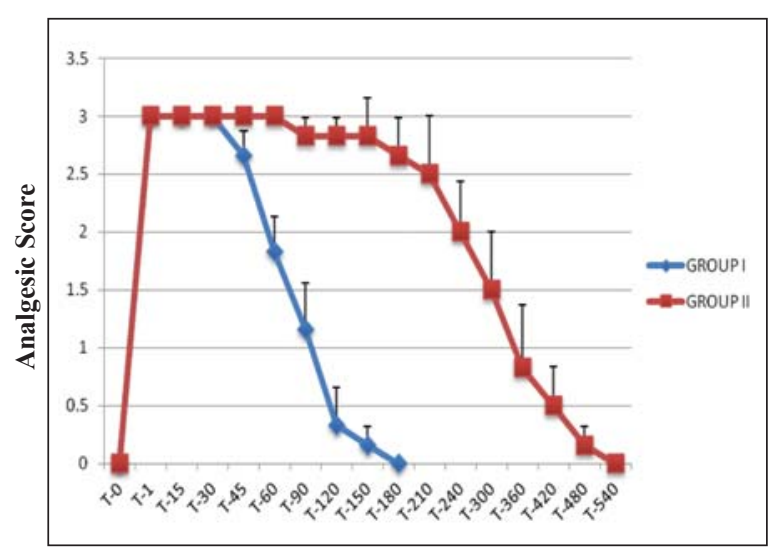

Time (minutes)

Figure 4. Loss and return of the anal reflex

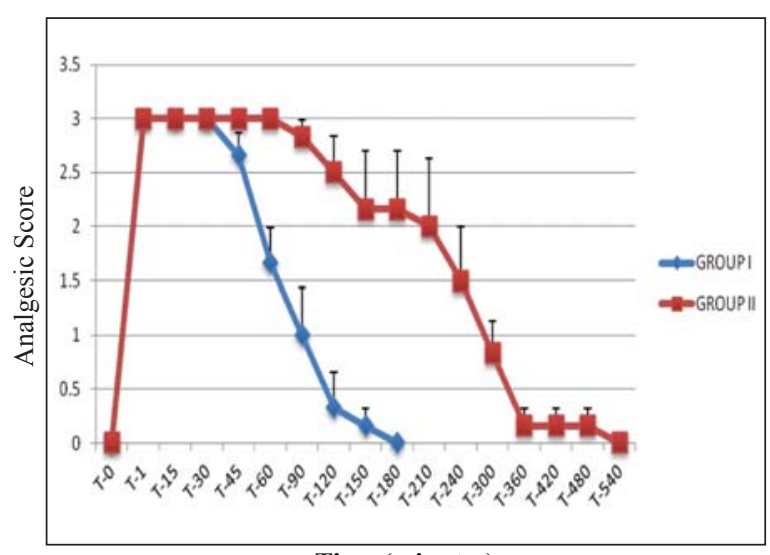

Time (minutes)

Figure 6. Analgesia of perineal region

The animals were generally comfortable in the cradle. However two animals, one each from Group I and II showed occasional struggling and/ or bleating irrespective of surgical stimulation while maintained in the Trendelenburg posture.

The anaesthetic induction time (mean \pm S.E) in animals of group I was significantly $(\mathrm{P}<0.5)$ shorter $(5.33 \pm 0.61 \mathrm{~min})$ than in those included in group II (12.67 $\pm 1.99 \mathrm{~min})$.

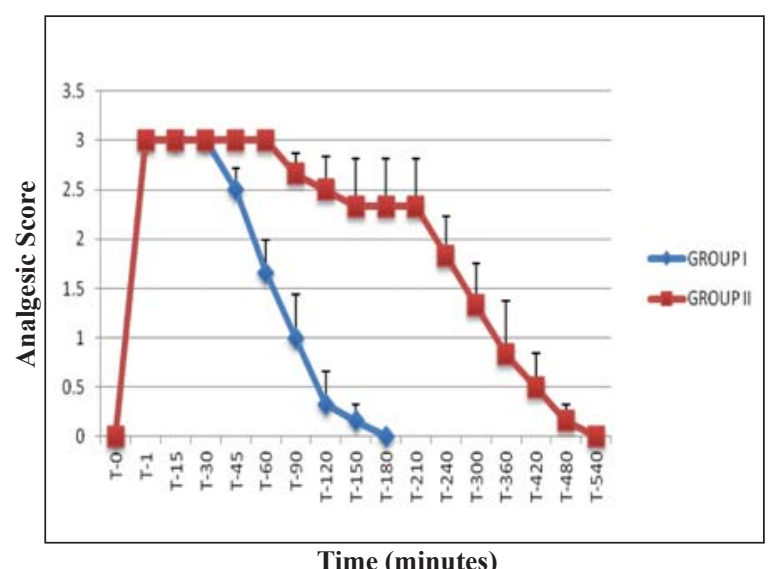

Figure 5. Analgesia of tail

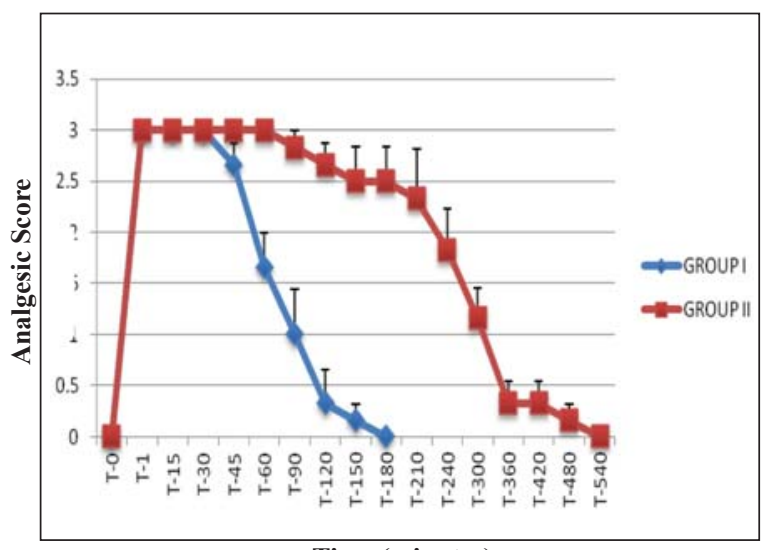

Time (minutes)

Figure 7. Loss and return of the pedal reflex

The duration of the actual laparoscopy and the total time required for surgery in goats of the two groups did not show any significant $(\mathrm{P}>0.05)$ difference.

Animals of both the groups showed significantly $(\mathrm{P}<0.05)$ higher (but within the normal range) heart rate up to T-150 when compared to their baseline value. Rectal temperature and respiration rates did not show any significant $(\mathrm{P}<0.05)$ difference both between and within the groups (Table 1). 


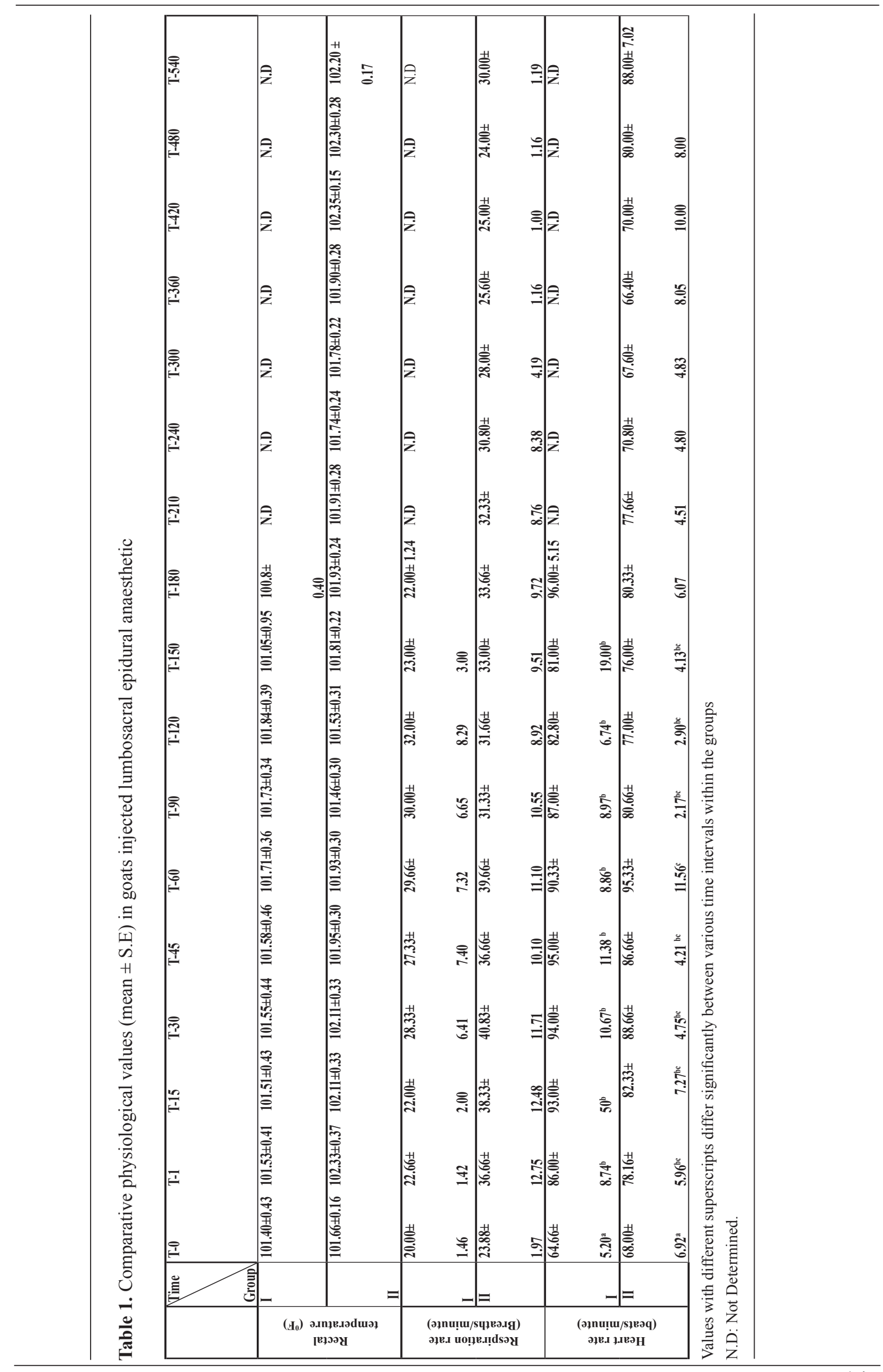




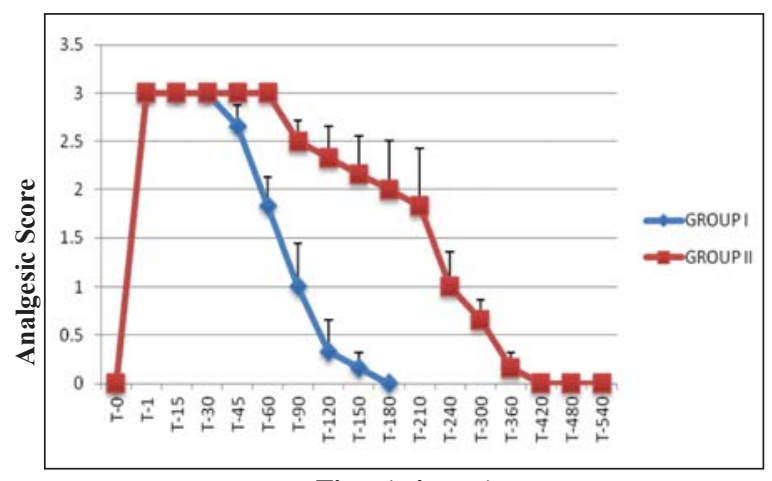

Time (minutes)

Figure 8. Analgesia of umbilicus

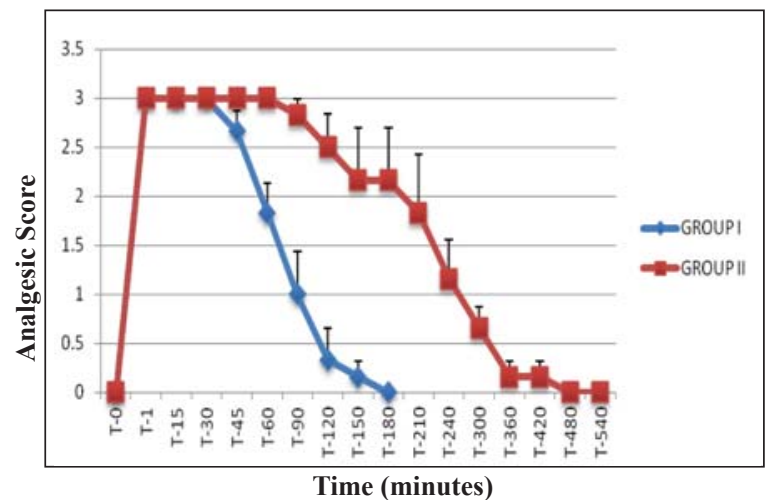

Figure 9. Analgesia of left umbilicus (paramedian)

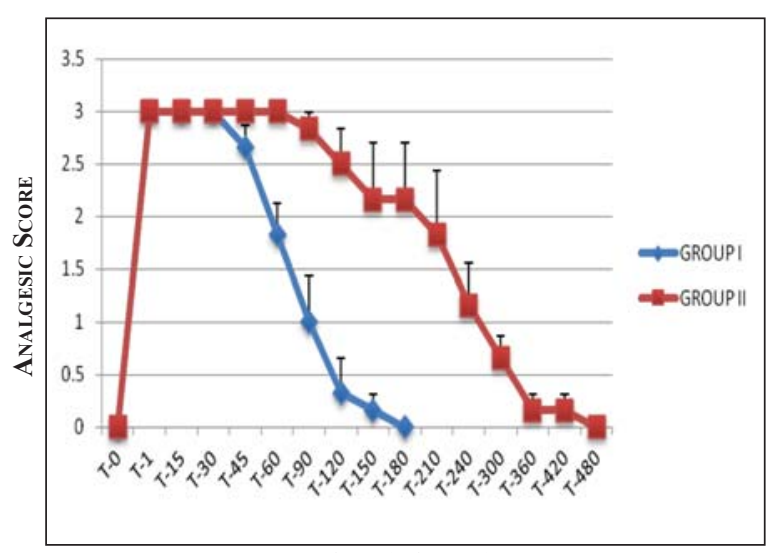

Time (minutes)

Figure 10. Analgesia of right umbilicus (paramedian)

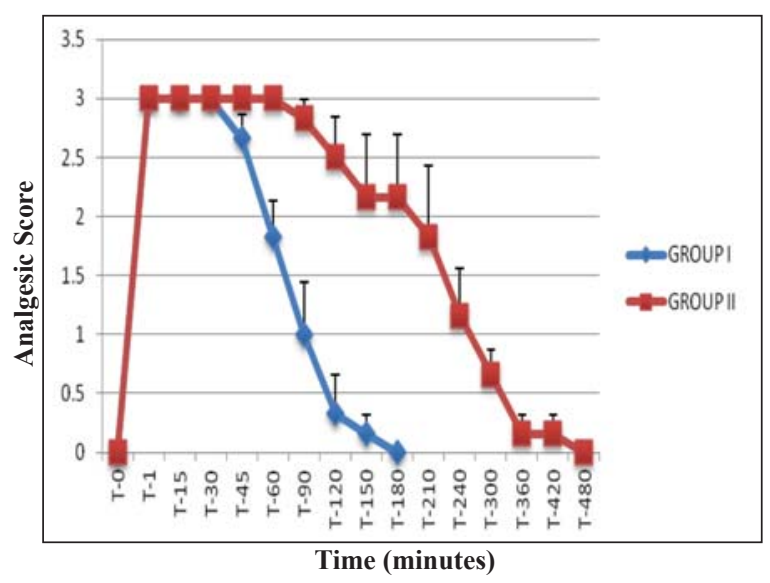

Figure 11. Analgesia of mid ventral abdomen

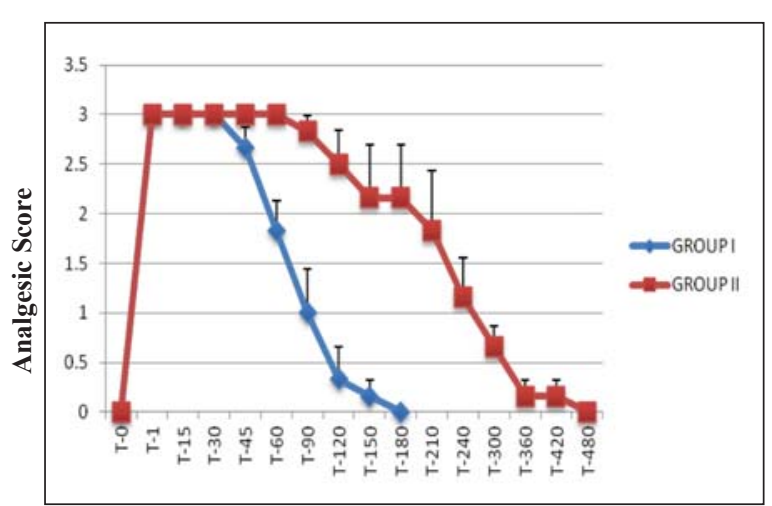

Time (minutes)

Figure 12. Analgesia of right abdomen (paramedian)

\section{DISCUSSION}

Lignocaine hydrochloride (2\%) and equipotent dose of ropivacaine hydrochloride $(0.5 \%)$ have been used in healthy goats undergoing laparoscopy assisted embryo transfer in this study.

The restraint of the animal against a wall in the standing position resulted in easy deposition of the local anaesthetic in the lumbosacral epidural space in the goats included in this study. The procedure was accomplished with minimal man power 146

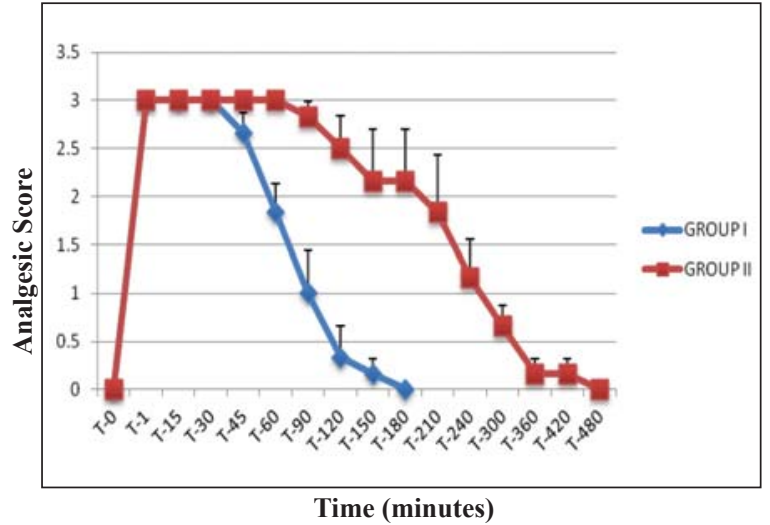

Figure 13. Analgesia of left abdomen (paramedian)

requirement and without distress to the animal. Lateral recumbency with the lumbosacral spine in full flexion has been used as an alternative way of restraint in small ruminants $(3,15,16)$ but may require more man power to restrain the animal and may also be comparatively more stressful to the animal.

Hypodermic needle was used without difficulty to inject local anaesthetic in the epidural space in goats. Conventionally the spinal needle is used for 
this purpose in most of the species. Spinal needle has a blunt tip that results in easy appreciation of the interarcuate ligament immediately over the epidural space. Additionally, the stylet within its lumen prevents the lodgment of the subcutaneous tissue core into the spinal canal (3). However, by careful and slow insertion of the hypodermic needle, difficulties or complications were not encountered in any of the animals included in this study. The diameter and the length of the needles (G-18, $3.85 \mathrm{~cm})$ were sufficient to deposit the local anaesthetic in the epidural space in all the goats. Smaller (3.25 $\mathrm{cm}$ ) hypodermic needles (G-18) have been used in two studies involving goats and sheep $(16,17)$. A 20-gauge, $3.50 \mathrm{~cm}$ needle has also satisfactorily been used for subarachnoid analgesia in goats (18). Rostami and Vesal (19) reported that in fat tailed sheep weighing $24.6 \pm 2.5 \mathrm{~kg}$ (range $21 \mathrm{~kg}-27 \mathrm{~kg}$ ), the mean distance from the skin to the epidural space was $3.4 \pm 0.3 \mathrm{~cm}$ (range $3.0 \mathrm{~cm}$ to $3.9 \mathrm{~cm}$ ).

The anal and hind quarters of the animals were kept at higher level immediately after injection of the drug to achieve its cranial spread within the spinal canal. Gravity by keeping the patient headup or head-down position may affect the spread of local anaesthetic solution within the epidural space (5). When the animal is allowed to stand on a level surface, anterior analgesia extends up to a fourth of the distance from the pubis to the umbilicus (5). The bilateral anaesthesia is possible if the animal is positioned prone or supine so that the vertebral canal is horizontal (20).

The animals of the two groups were subjected to a short period $(19.16 \pm 2.38$ and $13.16 \pm 2.53$ minutes respectively) of pneumoperitoneum. They were kept in Trendelenburg position only during this period. The position of Trendelenburg is convenient for cases in which it is desirable to allow the abdominal viscera to gravitate towards the diaphragm and thus facilitate visualization and manipulations in the pelvic region (21).

The signs of general discomfort observed occasionally in two animals, one from each group although showing satisfactory regional analgesia signify the need for incorporation of a sedative/ tranquilizer in the anaesthetic regimen of the goats undergoing laparoscopic surgery in Trendelenburg posture.

In the current study, $1 \mathrm{ml}$ of $2 \%$ lignocaine hydrochloride was used per $5.0 \mathrm{~kg}$ body weight (4 mg/kg) in animals of group I. The standard dose of lignocaine hydrochloride for anterior epidural anaesthesia in small ruminants is $1 \mathrm{ml} / 4.5$ to $7.0 \mathrm{~kg}$ body weight $(3,5)$. Ropivacaine, reportedly a well tolerated regional anaesthetic not only in human beings (13) but also in ruminants like buffaloes (14) and goats $(11,12)$, was used in animals of group II at dose rate of $1 \mathrm{mg} / \mathrm{kg}$ body weight. This dose rate was decided on the fact that ropivacaine hydrochloride is relatively 4 times more potent than lignocaine (4).

The volume of the two preparations was kept similar irrespective of the anaesthetic agent used. Many factors have been shown to affect the cranial spread of anaesthetic within the epidural space. The variables that can be controlled by the anaesthetist include positioning the patient, choosing the site of epidural puncture, orientation of the needle bevel, determining the volume and concentration of the anaesthetic solution, and the speed of injection (8). The anal and hind limb pedal reflex were absent and the tail and perineal analgesia profound during the initial 30 minutes of post-induction in animals of group I, but analgesia of the areas extended to 60 minutes in animals of group II. The various reflexes and responses returned to normal level quicker (180 min) in animals of group I than those of group II (540 $\mathrm{min}$ ). The comparatively shorter (360 min) time required for the return of full perineal sensation in cattle following caudal epidural block with ropivacaine reported in a recent study (22) might have resulted from a lower $(0.1 \mathrm{mg} / \mathrm{kg})$ dose of the drug used in that study. The analgesia in the umbilical and abdominal areas was complete at least for $30 \mathrm{~min}$ in animals under lignocaine hydrochloride epidural, but for $60 \mathrm{~min}$ in those injected $1 \mathrm{mg} / \mathrm{kg}$ ropivacaine hydrochloride. The mild analgesic effects also persisted for a long period (420 to $480 \mathrm{~min}$ ) in the latter group as compared to the former (180 min.) Unlike group I animals, the group II animals showed better analgesic score up to 180 minutes. The delay in regaining complete motor activity in the hind limbs was significantly longer (405 $\pm 46.31 \mathrm{~min}$ ) in animals of group II than those belonging to group I (130 $\pm 12.64 \mathrm{~min})$. Long duration of regional analgesia following the epidural use of ropivacaine in various animal species has been reported by several workers $(23,24,11)$.

All the physiological parameter values in goats included in both the groups were always in accordance with the species specific normal range $(15,18,25,26)$. The rectal temperature and respiration rate values showed non-significant increase, but significant increase in the heart rate was recorded up to 150 min in animals form both the groups following epidural injection of the anaesthetic. Physiological parameters, including heart rate, respiration rate 
and temperature are complex variables that can be altered by fear, stress, degree of anaesthesia, vascular volume, ambient temperature, muscular activity and metabolism $(27,28,29,30)$ but are not consistent or reliable indicators of pain (31). The physiological parameter values in the higher side of the normal range along with the occasional vocalization and struggling by two goats one from each group may indicate distress. The restraining of the goats in an un-physiologic Trendelenburg posture along with pneumoperitoneum is expected to put the animals under distress. In order to minimize stress, use of a preanaesthetic (sedative/tranquilizer) in addition to the epidural anaesthesia may therefore be explored in future (32).

\section{CONCLUSION}

Lumbosacral epidural injection of lignocaine hydrochloride $(4 \mathrm{mg} / \mathrm{kg})$ and ropivacaine hydrochloride $(1 \mathrm{mg} / \mathrm{kg})$ resulted in satisfactory regional anaesthesia without inducing major changes in their clinical parameters in adult goats undergoing laparoscopy assisted embryo transfer. The induction was quicker in goats injected lignocaine hydrochloride than those injected equipotent dose of ropivacaine hydrochloride. Due to the very long delay in regaining complete hind limb motor activity in animals that receive ropivacaine hydrochloride, this anaesthetic may not be recommended as a lumbosacral epidural anaesthetic drug in goats. Further supplementation of sedative/tranquilizer with lumbosacral epidural anaesthesia needs evaluation.

\section{REFERENCES}

1. Shin, S.T., Jang, S.K., Yang, H.S., Lee, O,K., Shim, Y.H., Choi, W.II., Lee, D.S., Lee, G.S., Cho, J.K., Lee, Y.W. (2008). Laparoscopy vs. laparotomy for embryo transfer to produce transgenic goats (Capra hircus). J. Vet. Sci. 9, 103-107. http://dx.doi.org/10.4142/jvs.2008.9.1.103 PMid:18296894 PMCid:PMC2839104

2. Dovenski T., Trojacanec P., Petkov V., PopovskaPercinic F., Kocoski Lj. Grizelj J. (2012). Laparoscopy-promising tool for improvement of reproductive efficiency of small ruminants. Mac Vet Rev 2012; 35(1): 5 - 11.

3. Hall, L.W., Clarke, K.W., Trim, C.M. (2001). Veterinary anaesthesia, fourth edition, W.B Saunders, Tottenham court road, London (U.K).
4. Lamont, L.A. (2002). Local anaesthetics in veterinary anaesthesia and pain management secrets. First edition. Hanley and Belfus, INC. Medical publishers, Philadelphia.

5. Skarda, R.T., Tranquilli, W.J. (2007). Local and regional anesthetic and analgesic techniques: Ruminant and swine. Lumb \& Jones' Veterinary Anesthesia and Analgesia. Fourth edition. Ames, IA: Blackwell Publishing. PMCid:PMC1852112

6. Edmondson, M.A. (2014). Local and regional anesthetic techniques in farm animal anesthesia. Lin, $\mathrm{H}$ and Walz, $\mathrm{P}$ (Eds.), first edition, Wiley Blackwell, Lowa, USA.

7. Gray, P.R., Mc Donell, W.N. (1986). Anesthesia in goats and sheep. Part I. Local analgesia. Compen. Contin. Edu. Pract. Vet. 8, S33-S39.

8. Ivany, J.M., Muir, W.W. (2004). Farm animal anesthesia. In: Farm animal surgery. Fubini, S.L and Ducharme, N.G (eds.), first edition, Saunders, Missouri.

9. Ala-Kokko, T.I., Partanen, A., Kainen, J., Kiviluoma, K., Alahuhta, S. (2000). Pharmacokinetics of $0.2 \%$ ropivacaine and $0.2 \%$ bupivacaine following caudal blocks in children. Acta Anaesthesiol. Scand. 44, 1099-1102.

http://dx.doi.org/10.1034/j.1399-6576.2000.440911.x PMid:11028730

10. Singh, K., Kinjavdekar., Amarpal., Aithal, H.P., Gopinathan, A., Singh, G.R., Singh, T., Pawde, A.M. Pratap, K. (2005). Clinicophysiological and hematobiochemical effects of epidural ropivacaine in uremic and healthy caprines. Indian J. Vet. Surg. 26, 11-15.

11. Ahmad, R., Shukla, B.P., Jain, R. (2011). Clinicophysiological changes following epidural analgesia by bupivacaine, ropivacaine or ropivacaine-xylazine combination in goats. Indian J. Vet. Surg. 32, 57-58.

12. Ahmad, R., Shukla, B.P. (2013). Haematobiochemical changes following epidural analgesia by bupivacaine, ropivacaine and ropivacainexylazine combination in goats. Indian J. Field Vet. 8, 47-51.

13. Kuthiala, G., Choudhary, G. (2011). Ropivacaine: A review of its pharmacology and its clinical use. Ind. J. Anaesth. 55,104-110.

14. Amarpal., Kinjavdekar, H., Aithal, H.P., Singh, G.R., Pawde, A., Singh, T., Sharma, N. Pratap, K. (2007). Comparison of two doses of ropivacaine for lumbosacral epidural analgesia in buffalo calves (Bubalus bubalis). Vet. Rec. 160, 766-769. http://dx.doi.org/10.1136/vr.160.22.766 PMid:17545647 
15. Kinjavdekar, P., Aithal, H.P., Amarpal., Pawde, A.M., Pratap, K., Singh, G.R. (2006). Potential effect of romifidine with lidocaine administration in goats. Small Rumin. Res. 64, 293-304. http://dx.doi.org/10.1016/j.smallrumres.2005.04.029

16. Dadafarid, H., Najafpour, A. (2008). Hematochemical changes following epidural analgesia by bupivacaine, ketamine and their combination in Chall sheep. J. Anim. Vet. Adv. 7, 1524-1527.

17. Adetunji, A., Ajadi, R.A., Opia, R.E. (2002). A comparison of epidural anaesthesia with xylazine, bupivacaine and bupivacaine/xylazine mixture in West African dwarf goats. Isr. J. Vet Med. 57, 74-80.

18. De Rossi, R., Junqueira, A.L., Lopes, R.A., Beretta, M.P. (2005). Use of ketamine or lidocaine or in combination for subarachnoid analgesia in goats. Small Rumin. Res. 59, 95-101. http://dx.doi.org/10.1016/j.smallrumres.2004.11.009

19. Rostami, M., Vesal, N. (2012). The effects of adding epinephrine or xylazine to lidocaine solution for lumbosacral epidural analgesia in fat-tailed sheep. J. S. Afri. Vet. Assoc. 83, 1-7. http://dx.doi.org/10.4102/jsava.v83i1.1 PMid:23327124

20. Amnikov, B. (1999). Epidural administration of xylazine-lidocaine mixture in sheep-analgesic and cardiopulmonary effects. Vet. Arhive 69, 327-333.

21. Franz, S., Dadak, A.M., Khol, J.L., Damaso, A., Baumgartner, W. (2009). Laparoscopic performed cystotomy and catheter implantation in male sheep. Vet. Med. 54, 367-373.

22. Araujo, M.A., Albuquerque, V.B., Deschk, M., Santos, G.G.F., Rodrigues, C.A., Oliva, V.N.L.S., Santos, P.S.P. (2012). Cardiopulmonary and analgesic effects of caudal epidurally administered ropivacaine in cattle. Vet. Anaesth. Analg. 39, 409413.

http://dx.doi.org/10.1111/j.1467-2995.2012.00726.x PMid:22574815

23. Skarda, R.T., Muir, W.W. (2001). Analgesia, hemodynamic and respiratory effects of caudal epidurally administered ropivacaine hydrochloride in mares. Vet. Anaesth. Analg. 28, 61-74. http://dx.doi.org/10.1046/j.1467-2995.2001.00025.x
24. Duke, T., Caulkett, N.A., Ball, H.S., Remedios, A.M. (2000). Comparative analgesia and cardiopulmonary effects of bupivacaine and ropivacaine in the epidural space of conscious dogs. Vet. Anaesth. Analg. 27, 13-21.

http://dx.doi.org/10.1046/j.1467-2995.2000.00001.x

25. Sadegh, A.B., Shafiei, Z., Nazhvani, S.D. (2009). Comparison of epidural anesthesia with lidocainedistilled water and lidocaine-magnesium sulfate mixture in goat. Vet. Arh. 79, 1-17.

26. Aithal,H.P.,Amarpal., Pratap, K., Singh, G.R.(1996). Clinical effects of epidurally administered ketamine and xylazine in goats. Small Rumin. Res. 24, 55-64. http://dx.doi.org/10.1016/S0921-4488(96)00919-4

27. Keskin, M., Biçer, O., Gül, S., Sarı, A. (2006). A study on comparison of some physiological adaptation parameters of different goat genotypes under the eastern Mediterranean climatical condition. Hayvansal Üretim. 47, 16-20.

28. Devendra, C. (1987). Bioclimatology and the adaptation of livestock. In: Johnson H.P. (Ed.), Goats. Elsevier Publ., 157, Holland, pp. 16-77.

29. Habibian, S., Bigham, A.S., Aali, E. (2011). Comparison of lidocaine, tramadol and lidocainetramadol for epidural analgesia in lambs. Res. Vet. Sci. 91, 434-438.

http://dx.doi.org/10.1016/j.rvsc.2010.09.023 PMid:21036376

30. De Rossi, R., Silva-Neto, A.B., Pompermeyer, C.T.D., Frazílio, F.O., Paulo, H.A., Jardim, A.C.L. (2012). The efficacy and safety of levobupivacaine administered by lumbosacral epidural route in conscious sheep. Res. Vet. Sci. 92, 278-282. http://dx.doi.org/10.1016/j.rvsc.2010.11.006 PMid:21167540

31. Conzemius, M.G., Hill, C.M., Sammarco, J.L., Perkowski, S.Z. (1997). Correlation between subjective and objective measures used to determine severity of postoperative pain in dogs. J. Am. Vet. Med. Assoc. 210, 1619-1622. PMid:9170089

32. Lin, H. (2014). Commonly used preanesthetics. In: Farm animal anesthesia. Lin, $\mathrm{H}$ and Walz, $\mathrm{P}$ (editors), first edition, Wiley Blackwell, Lowa, USA. http://dx.doi.org/10.1002/9781118886700 